\title{
Estimating root zone soil moisture using near-surface observations from SMOS
}

\author{
T. W. Ford, E. Harris, and S. M. Quiring \\ Department of Geography, Texas A\&M University, College Station, Texas, USA
}

Correspondence to: T. W. Ford (twford@tamu.edu)

Received: 31 May 2013 - Published in Hydrol. Earth Syst. Sci. Discuss.: 28 June 2013

Revised: 25 November 2013 - Accepted: 29 November 2013 - Published: 13 January 2014

\begin{abstract}
Satellite-derived soil moisture provides more spatially and temporally extensive data than in situ observations. However, satellites can only measure water in the top few centimeters of the soil. Root zone soil moisture is more important, particularly in vegetated regions. Therefore estimates of root zone soil moisture must be inferred from nearsurface soil moisture retrievals. The accuracy of this inference is contingent on the relationship between soil moisture in the near-surface and the soil moisture at greater depths. This study uses cross correlation analysis to quantify the association between near-surface and root zone soil moisture using in situ data from the United States Great Plains. Our analysis demonstrates that there is generally a strong relationship between near-surface $(5-10 \mathrm{~cm})$ and root zone $(25-60 \mathrm{~cm})$ soil moisture. An exponential decay filter is used to estimate root zone soil moisture using near-surface soil moisture derived from the Soil Moisture and Ocean Salinity (SMOS) satellite. Root zone soil moisture derived from SMOS surface retrievals is compared to in situ soil moisture observations in the United States Great Plains. The SMOSbased root zone soil moisture had a mean $R^{2}$ of 0.57 and a mean Nash-Sutcliffe score of 0.61 based on 33 stations in Oklahoma. In Nebraska, the SMOS-based root zone soil moisture had a mean $R^{2}$ of 0.24 and a mean Nash-Sutcliffe score of 0.22 based on 22 stations. Although the performance of the exponential filter method varies over space and time, we conclude that it is a useful approach for estimating root zone soil moisture from SMOS surface retrievals.
\end{abstract}

\section{Introduction}

Root zone soil moisture in vegetated regions has a significant influence on evapotranspiration rates (McPherson, 2007; Alfieri et al., 2008). Soil moisture is vital to land-atmosphere interactions, and has been shown to modulate drought conditions, especially in semi-arid environments such as the North American Great Plains (Koster et al., 2004). Several studies show that soil moisture can influence land atmosphere interactions through modification of energy and moisture fluxes in the boundary layer (Pal and Eltahir, 2001; Basara and Crawford, 2002; Taylor et al., 2007). Frye and Mote (2010) found that soil moisture and soil moisture gradients in the southern Great Plains significantly influence convective initiation under synoptic conditions not otherwise conducive to convection. Taylor et al. (2012) found that afternoon convective precipitation in the Sahel region of Africa preferentially falls over dry soil, most likely due to enhanced sensible heat flux by anomalously low soil moisture. Despite the important role that soil moisture plays in the climate system (Legates et al., 2011), there are relatively few stations that measure soil moisture as compared to stations that measure temperature and precipitation. This impedes observation-based analyses of soil moisture-climate interactions.

Soil moisture in the North American Great Plains exhibits high variability both annually and interannually (Illston et al., 2004). Soil moisture not only varies over space and time, but also with depth in the soil column (Mahmood and Hubbard, 2004). Georgakakos and Bae (1994) evaluated soil moisture variability in the midwestern United States using a conceptual model and found that the persistence of soil moisture in the deeper soil was much greater than the persistence of nearsurface soil moisture. Wu and Dickinson (2004) examined 
Table 1. Synopsis of recent and future satellite soil moisture missions.

\begin{tabular}{llrlll}
\hline Mission & $\begin{array}{l}\text { Temporal } \\
\text { Resolution }\end{array}$ & $\begin{array}{r}\text { Spatial } \\
\text { Resolution }(\mathrm{km})\end{array}$ & Type & $\begin{array}{l}\text { EMR- } \\
\text { Band }\end{array}$ & $\begin{array}{l}\text { Mission } \\
\text { Website }\end{array}$ \\
\hline SSM/I & Daily & 25 & Passive & $\mathrm{C}$ & http://podaac.jpl.nasa.gov/SSMI \\
TRMM TM & Daily & $50-56$ & Passive & $\mathrm{C}$ & http://trmm.gsfc.nasa.gov/ \\
Aqua AMSR-E & Daily & 56 & Passive & $\mathrm{C}$ & http://aqua.nasa.gov/ \\
ERS 1-2 SCAT & 35 days & $25-50$ & Active & $\mathrm{C}$ & http://www.ipf.tuwien.ac.at \\
SMOS & 3 days & 50 & Passive & $\mathrm{L}$ & http://ilrs.gsfc.nasa.gov/missions/ \\
SMAP & 2-3 days & $10-40$ & Both & $\mathrm{L}$ & http://smap.jpl.nasa.gov/ \\
MetOp ASCAT & 29 days & 50 & Active & $\mathrm{C}$ & http://www.ipf.tuwien.ac.at/ \\
\hline
\end{tabular}

soil moisture variability using the National Center for Atmospheric Research Community Climate Model, version 3 (NCAR CCM3). They found that correlations between the near-surface and root zone soil moisture vary seasonally. Wu et al. (2002) studied the variability of soil moisture observations in Illinois and found that soil wetness influences how quickly soil wetting/drying moves through the soil column.

Mahmood and Hubbard (2007) used a soil-water energy balance model to examine the relationship between nearsurface and root zone soil moisture in Nebraska. Their results showed that cross correlations between near-surface and root zone soil moisture data sets exhibited high variability across Nebraska due to differences in soil, land use and climatic conditions. However, they concluded that it is possible to accurately estimate root zone soil moisture based on nearsurface soil moisture. Mahmood et al. (2012) examined the predictability of soil moisture at various depths in Nebraska. They found that, in general, root zone soil moisture can be accurately estimated using $10 \mathrm{~cm}$ observations. However, estimation accuracy depends on the prevailing climatological conditions. In general, predictions of root zone soil moisture are more accurate in locations that receive more precipitation (i.e., soils with higher water content) (Mahmood and Hubbard, 2007; Mahmood et al., 2012). Overall, previous studies have suggested that soil moisture in the root zone is correlated with near surface soil moisture. Therefore, satellite soil moisture retrievals may provide an accurate means of estimating water content in the root zone.

In situ measurements of soil moisture are limited in their spatial and temporal extent (Prigent et al., 2005; Reichle and Koster, 2005). Satellites provide more extensive spatial coverage and have a temporal resolution ranging from 1 to $35+$ day(s). There are many different satellite missions that collect soil moisture data. Table 1 summarizes information about these satellite missions. The satellites assess soil wetness using either the C-band $(4-8 \mathrm{GHz})$ or the L-band $(1-2 \mathrm{GHz})$. Each of these platforms is currently in use, except for the SMAP (Soil Moisture Active Passive) mission, which is scheduled to launch in November 2014 and will provide global soil moisture measurements every 2-3 days (Entekhabi et al., 2010). The first satellite mission to fo- cus primarily on the collection of soil moisture data was the Soil Moisture Ocean Salinity (SMOS) satellite (Kerr et al., 2010, 2012). The European Space Agency (ESA) launched the SMOS satellite in October 2010. SMOS uses microwave radiometry for estimating soil moisture (Kerr et al., 2010, 2012). L-band radiometry is achieved through 69 small antennae, resulting in a ground resolution of $50 \mathrm{~km}$ (Kerr et al., 2010, 2012).

Several studies have compared SMOS estimates to in situ soil moisture data. Jackson et al. (2012) used a set of relatively dense in situ soil moisture observation sites to validate SMOS retrievals over USDA Agricultural Research Service experimental watersheds. Their results showed that SMOS soil moisture estimates are in relatively good agreement with soil moisture observations. Al Bitar et al. (2012) compared SMOS soil moisture estimates with in situ soil moisture observations from Soil Climate Network (SCAN) and SNOwpack TELemetry (SNOTEL) observation network stations throughout several regions of the United States. The results of their node-to-node validation revealed that the accuracy of SMOS soil moisture estimates vary significantly from site to site. Collow et al. (2012) compared SMOS-derived soil moisture to in situ measurements in the US Great Plains to evaluate the accuracy of the satellite measurements. They concluded that evaluating SMOS is difficult due to the lack of uniform soil moisture measurements.

SMOS measures soil water content in the top few centimeters and thus cannot directly determine root zone soil moisture conditions. Therefore, it is important to evaluate the degree of association between near-surface and root zone soil moisture when attempting to estimate root zone moisture using satellite retrievals. Previous studies have estimated root zone soil moisture (or soil wetness index) using only surface observations. Root zone soil moisture has been estimated from satellite surface soil moisture retrievals from a number of different platforms, including the ERS (European remote sensing) scatterometer (Wagner et al., 1999; Ceballos et al., 2005) and ASCAT (advanced scatterometer; Albergel et al., 2009; Brocca et al., 2010, 2011, 2013). The recursive exponential filter has also been previously applied to both in situ and model-estimated soil moisture (Albergel et al., 2008; 


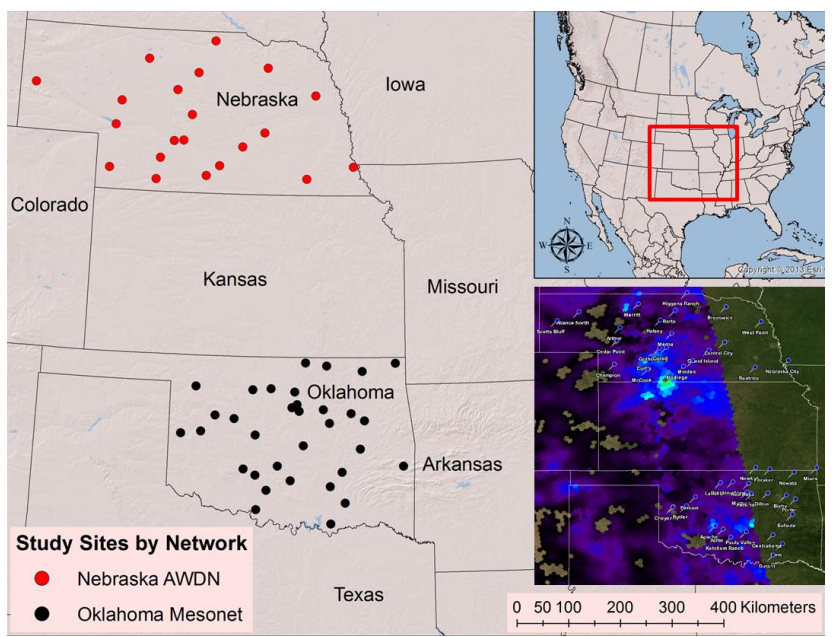

Fig. 1. Soil moisture stations from the Nebraska Automated Weather Data Network and Oklahoma Mesonet that are used in this study. Automated Weather Data Network sites are red and Oklahoma Mesonet sites are dark blue. The lower right inset map shows a representative SMOS footprint from 6 June 2011 and the locations of stations in Oklahoma and Nebraska.

Barbu et al., 2011). Albergel et al. (2008) applies an exponential filter to in situ soil moisture observations at a point scale and model estimates in France at a national scale. Albergel et al. (2010) compares the output of the exponential filter to soil moisture from a land data assimilation system at one site in southwestern France. The accuracy of these methods for deriving root zone soil moisture estimates from SMOS have not been evaluated using North American soil moisture observations. This study characterizes and quantifies the strength of the relationship between soil moisture in the near-surface and deeper soil and how it varies over time and space. In situ soil moisture observations over the North American Great Plains are used to calibrate an exponential filter model. This exponential filter is then employed to evaluate its utility for estimating root zone soil wetness from SMOS surface retrievals. The accuracy of the SMOS-derived estimates of root zone soil moisture are determined using observations from Oklahoma and Nebraska.

\section{Data and methods}

\subsection{Study region}

The North American Great Plains have a significant westeast precipitation gradient and north-south temperature gradient (Meng and Quiring, 2010). Vegetation and soil conditions exhibit great spatial variability across the region. Koster et al. (2004) characterize the southern Great Plains as a "hotspot" of land-atmosphere interactions. That is, this is a region where soil moisture and precipitation are strongly coupled. The southern Great Plains contains one of several
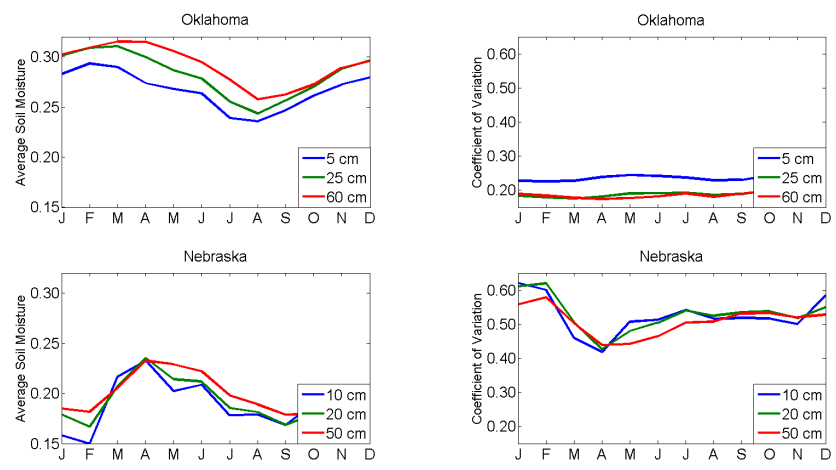

Fig. 2. Mean monthly soil moisture $\left(\mathrm{cm}^{3} \mathrm{~cm}^{-3}\right)$ in Oklahoma (top left) and Nebraska (bottom left) and mean monthly coefficient of variation in Oklahoma (top right) and Nebraska (bottom right). Blue lines represent the near-surface soil $(5$ or $10 \mathrm{~cm})$ while the green and red lines represent soil moisture at 20 or $25 \mathrm{~cm}$ and 50 or $60 \mathrm{~cm}$, respectively.

SMAP test bed sites that are used to validate satellite soil moisture retrievals using in situ observations (Cosh et al., 2010). The Great Plains region was selected for this study because of the relatively high density of soil moisture observations.

Daily volumetric soil water content estimates are from the Oklahoma Mesonet, www.mesonet.org, and Nebraska Automated Weather Data Network (AWDN, http://www.hprcc. unl.edu/awdn/). The Oklahoma Mesonet operates more than 100 stations that measure meteorological variables on daily and sub-daily resolutions across Oklahoma (Illston et al., 2008). Volumetric soil water content is estimated at Oklahoma Mesonet sites from the matrix potential using Campbell Scientific 229-L sensors at 5, 25, 60 and $75 \mathrm{~cm}$. The AWDN similarly operates meteorological stations across the northern Great Plains (You et al., 2010). AWDN estimates volumetric soil water content using Steven's Hydra Probes placed at 10, 25, 50 and $100 \mathrm{~cm}$ in the soil column. The Oklahoma Mesonet soil moisture data analyzed span the period 2000-2012 and are at a daily resolution while AWDN data are available from 2006 to 2010 also at a daily resolution. Volumetric water content data from 33 Oklahoma Mesonet sites and 22 AWDN sites are used in this study (Fig. 1). The sites were selected based on the length of record and completeness of the soil moisture data. All soil moisture data were quality controlled and distributed by the North American Soil Moisture Database at Texas A\&M University (http://soilmoisture.tamu.edu).

\subsection{Soil moisture data}

Table 2 provides descriptive statistics of soil moisture in the near-surface $(5 \mathrm{~cm})$ and root zone $(25$ and $60 \mathrm{~cm})$ averaged over all sites in Oklahoma. All values shown in Table 2 are in units of volumetric soil water content $\left(\mathrm{cm}^{3} \mathrm{~cm}^{-3}\right)$. In general soil moisture content in the near-surface correlates strongly 
Table 2. Descriptive statistics for Oklahoma and Nebraska soil moisture. Table shows the mean, maximum, minimum, range and coefficient of variation $(\mathrm{CV})$ averaged over all sites. All values are volumetric soil water content $\left(\mathrm{cm}^{3} \mathrm{~cm}^{-3}\right)$ units.

\begin{tabular}{|c|c|c|c|c|c|c|c|}
\hline \multicolumn{4}{|c|}{ Oklahoma } & \multicolumn{4}{|c|}{ Nebraska } \\
\hline & Average & Maximum & Minimum & & Average & Maximum & Minimum \\
\hline Mean $5 \mathrm{~cm}$ & 0.27 & 0.39 & 0.19 & Mean $10 \mathrm{~cm}$ & 0.19 & 0.32 & 0.07 \\
\hline Mean $25 \mathrm{~cm}$ & 0.28 & 0.35 & 0.21 & Mean $20 \mathrm{~cm}$ & 0.19 & 0.35 & 0.07 \\
\hline Mean $60 \mathrm{~cm}$ & 0.29 & 0.38 & 0.19 & Mean $50 \mathrm{~cm}$ & 0.20 & 0.35 & 0.07 \\
\hline Max $5 \mathrm{~cm}$ & 0.32 & 0.48 & 0.21 & $\operatorname{Max} 10 \mathrm{~cm}$ & 0.30 & 0.43 & 0.13 \\
\hline $\operatorname{Max} 25 \mathrm{~cm}$ & 0.33 & 0.42 & 0.24 & $\operatorname{Max} 20 \mathrm{~cm}$ & 0.29 & 0.43 & 0.10 \\
\hline Max $60 \mathrm{~cm}$ & 0.33 & 0.42 & 0.22 & Max $50 \mathrm{~cm}$ & 0.29 & 0.42 & 0.11 \\
\hline Min $5 \mathrm{~cm}$ & 0.20 & 0.28 & 0.16 & Min $10 \mathrm{~cm}$ & 0.07 & 0.17 & 0.02 \\
\hline $\operatorname{Min} 25 \mathrm{~cm}$ & 0.21 & 0.28 & 0.16 & Min $20 \mathrm{~cm}$ & 0.08 & 0.25 & 0.00 \\
\hline $\operatorname{Min} 60 \mathrm{~cm}$ & 0.23 & 0.30 & 0.17 & Min $50 \mathrm{~cm}$ & 0.10 & 0.24 & 0.02 \\
\hline Range $5 \mathrm{~cm}$ & 0.13 & 0.26 & 0.05 & Range $10 \mathrm{~cm}$ & 0.22 & 0.32 & 0.10 \\
\hline Range $25 \mathrm{~cm}$ & 0.12 & 0.23 & 0.05 & Range $20 \mathrm{~cm}$ & 0.21 & 0.31 & 0.09 \\
\hline Range $60 \mathrm{~cm}$ & 0.10 & 0.18 & 0.05 & Range $50 \mathrm{~cm}$ & 0.19 & 0.28 & 0.09 \\
\hline CV $5 \mathrm{~cm}$ & 0.14 & 0.25 & 0.05 & $\mathrm{CV} 10 \mathrm{~cm}$ & 0.32 & 0.47 & 0.17 \\
\hline $\mathrm{CV} 25 \mathrm{~cm}$ & 0.13 & 0.22 & 0.07 & $\mathrm{CV} 20 \mathrm{~cm}$ & 0.29 & 0.43 & 0.09 \\
\hline $\mathrm{CV} 60 \mathrm{~cm}$ & 0.12 & 0.20 & 0.06 & $\mathrm{CV} 50 \mathrm{~cm}$ & 0.28 & 0.48 & 0.08 \\
\hline
\end{tabular}

with soil moisture at deeper layers. Average soil moisture content at Oklahoma sites is generally higher than at Nebraska sites, while daily variability, as measured by the coefficient of variation (CV), is higher at the Nebraska sites. Soil moisture from both networks exhibits strong seasonal variability. Figure 2 displays mean monthly soil moisture and $\mathrm{CV}$ for each network. Mean monthly soil moisture in Oklahoma peaks in early spring followed by drying throughout spring and summer. Soil moisture recharge occurs during the winter months. These patterns are similar to those reported by Illston et al. (2004). There is relatively little intra-annual variation in mean monthly $\mathrm{CV}$, although soil moisture at $5 \mathrm{~cm}$ is consistently more variable than at 25 and $60 \mathrm{~cm}$. Mean monthly soil moisture from Nebraska shows similar patterns to Oklahoma. However, the timing of the maximum and minimum soil moisture is several weeks later in Nebraska. The period between March and May corresponds with lowest soil moisture variability in Nebraska.

Soil moisture in Oklahoma and Nebraska also exhibits significant spatial variability. To characterize the west-east gradient in Great Plains soil moisture, driven by strong gradients in precipitation, we binned Oklahoma and Nebraska stations according to their longitude. Figure 3 shows the mean volumetric soil water content for (a) Oklahoma and (b) Nebraska. Stations in the eastern portion of both states generally exhibit higher average volumetric soil water content than those in the west. Mahmood et al. (2012) found that coupling between root zone and near-surface soil moisture in Nebraska was stronger at locations with wetter climate/soils. Therefore we should expect to find stronger coupling between surface and root zone soil moisture at sites with wetter climatic conditions (eastern Oklahoma and eastern Nebraska).
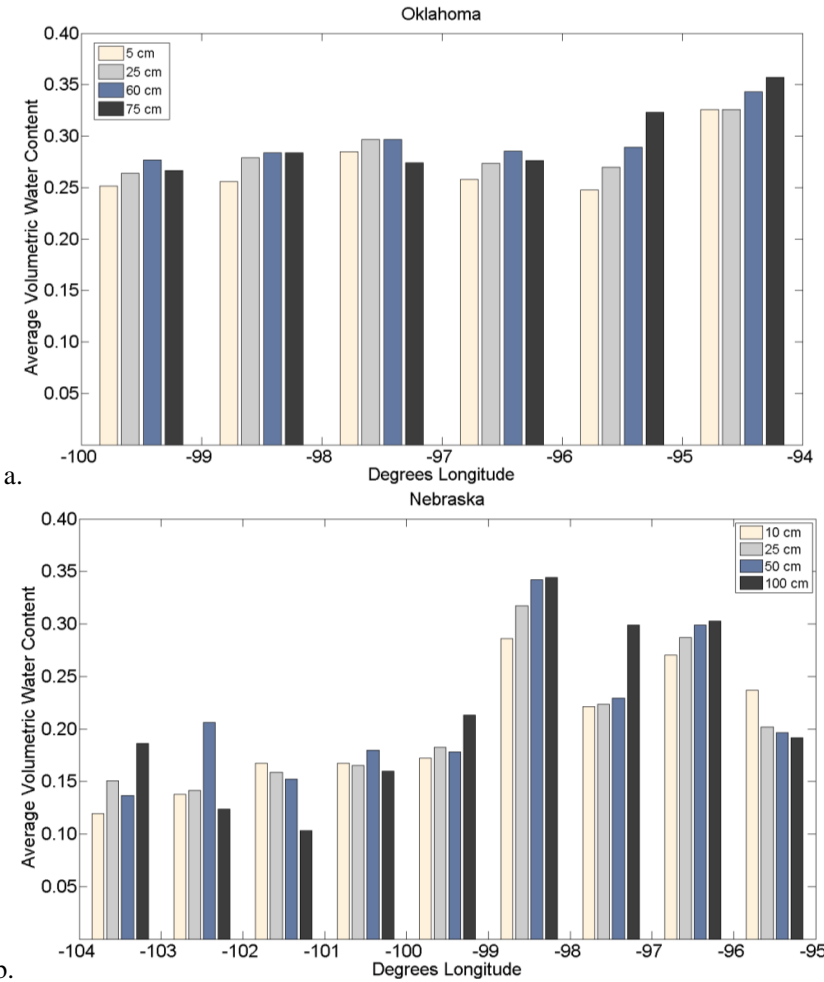

Fig. 3. Oklahoma Mesonet (a) and AWDN (b) stations are binned by the station's longitude. Bar graphs show the average volumetric soil water content for each bin at each measurement depth. 

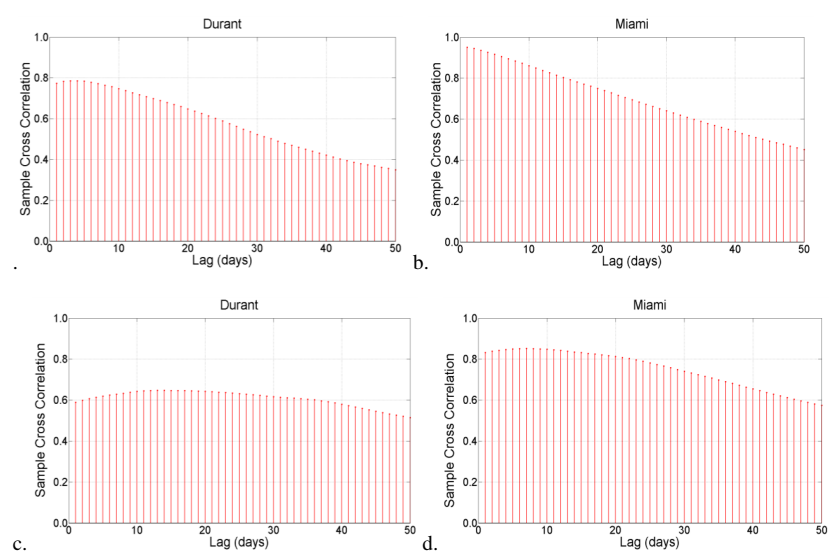

Fig. 4. Sample cross correlations at two Oklahoma stations: (a) and (c) show 5-25 cm and 5-60 cm cross correlations at Durant, Oklahoma and (b) and (d) show 5-25 cm and 5-60 cm cross correlations at Miami, Oklahoma.

\subsection{Methods}

Two methods used in previously published studies were employed to characterize the relationship and coupling strength between near-surface and root zone layer soil moisture in Oklahoma and Nebraska (Albergel et al., 2008; Mahmood et al., 2012). The first method calculates lagged cross correlation coefficients between near-surface soil moisture observations (at 5 or $10 \mathrm{~cm}$ ) and those deeper in the soil (at 25 and 50 or $60 \mathrm{~cm}$ ). Daily root zone soil moisture data is lagged 25 days with respect to the near-surface soil moisture data. Maximum lagged cross correlation coefficients between the two depths are evaluated as well as the lag time (in days) at which the maximum cross correlation was attained. Mahmood et al. (2012) used a similar methodology when examining the relationship between soil moisture at various depths in Nebraska. Cross correlation coefficients characterize the association between soil moisture in the near-surface and soil moisture in the root zone. When the correlations are small, this indicates that the near-surface and root zone are weakly coupled and therefore near-surface soil moisture has limited utility for predicting root zone soil moisture.

After examining the soil moisture coupling, we evaluate a method for inferring root zone soil moisture from nearsurface observations. Previous studies have evaluated various forms of ensemble or extended Kalman filtering (Crow and Wood, 2003; Sabater et al., 2007; Draper et al., 2009; Hain et al., 2012) for estimating root zone soil moisture and land data assimilation for land surface models. For instance, Draper et al. (2009) found that the extended Kalman filter was useful for assimilating AMSR-E data into a land surface scheme. $\mathrm{Li}$ et al. (2012) employed a Kalman smoothing method to assimilate GRACE terrestrial water storage into the NASA catchment land surface model. In contrast, Hsu et al. (2012) found success employing a sequential Monte Carlo particle-
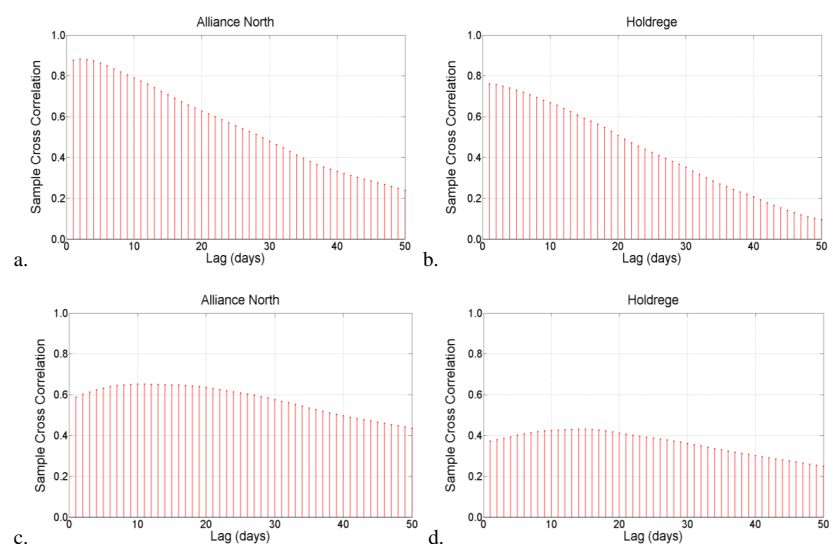

Fig. 5. Sample cross correlations at two Nebraska stations: (a) and (c) show $10-25 \mathrm{~cm}$ and $10-50 \mathrm{~cm}$ cross correlations at Alliance North, Nebraska and (b) and (d) show $10-25 \mathrm{~cm}$ and $10-50 \mathrm{~cm}$ cross correlations at Holdrege, Nebraska.

filter technique to assimilate AMSR-E data into the Noah land surface model. These land data assimilation schemes are typically employed to correct soil moisture when measurements of root zone soil moisture are not available (Albergel et al., 2010). On the other hand, the exponential filter method estimates root zone soil moisture in areas where only surface soil moisture is available and this method is better suited for near-real time monitoring of soil moisture conditions.

In this study we evaluate the utility of the exponential filter method described by Albergel et al. (2008) for estimating root zone soil moisture from near-surface observations. The filter uses near-surface soil moisture observations and applies an exponential decay function to estimate root zone soil moisture. Previous studies have successfully employed similar methods to estimate root zone soil moisture in different regions of the world and using various satellite platforms (Wagner et al., 1999; Albergel et al., 2009; Brocca et al., 2010). Our study evaluates the utility of this method for assimilating root zone soil moisture based on SMOS-derived surface soil moisture. The advantages of the exponential filter method are that it is easy to implement and it is computationally efficient. This method is particularly useful when only surface soil moisture data are available.

This study investigates three questions: (1) are surface and root zone soil moisture strongly related? (2) Can the exponential filter be used to predict root zone soil moisture? (3) How accurate are SMOS-based estimates of root zone soil moisture derived using the exponential filter? The results section of this paper is organized around these three questions. 


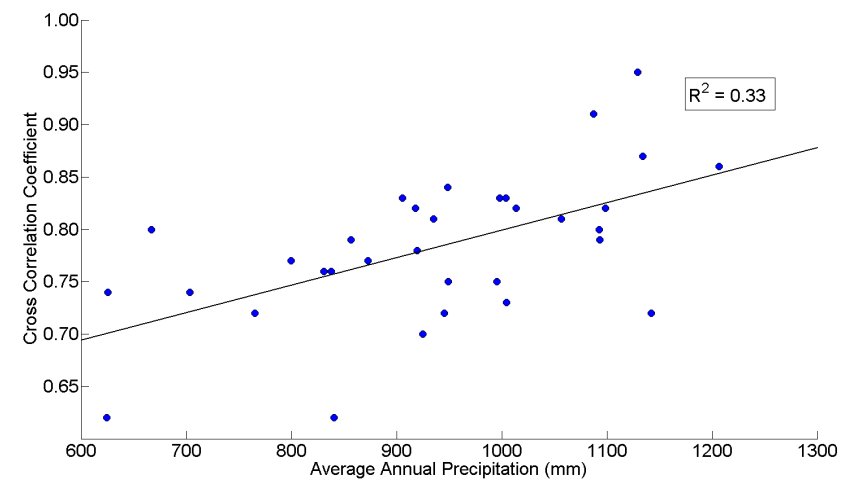

Fig. 6. Peak cross correlation $(r)$ between the 5 and $25 \mathrm{~cm}$ layers for all Oklahoma sites versus the average annual precipitation. Each point represents one site.

\section{Results}

\subsection{Cross correlation results}

The 5-25 cm cross correlation in Durant and Miami, Oklahoma have pronounced peaks in strength with a $\sim 5$ day lag (Fig. 4a, b). Similar patterns are shown in $10-25 \mathrm{~cm}$ cross correlation plots for Alliance North and Holdrege, Nebraska (Fig. 5a, b). The cross correlations in the $5-60 \mathrm{~cm}$ (Fig. 4c, d) and $10-50 \mathrm{~cm}$ (Fig. $5 \mathrm{c}$, d) are weaker and have lag times that are approximately $5-10$ days longer.

Greater than $30 \%$ of Oklahoma Mesonet soil moisture data at the $75 \mathrm{~cm}$ depth was missing, therefore we did not evaluate cross correlations at this depth. The maximum 5$25 \mathrm{~cm}$ cross correlation at Oklahoma sites ranged from 0.62 to 0.95 with an overall average of 0.78 . The lag times for 5$25 \mathrm{~cm}$ ranged from 0 to 4 days with an overall average of 2 days. Not surprisingly, maximum 5-60 cm cross correlations were generally weaker than the $5-25 \mathrm{~cm}$. This supports the findings of Wu et al. (2002) that coupling strength between soil layers decreases as depth increases. Maximum 5-60 cm cross correlations in Oklahoma ranged from 0.43 to 0.86 at Woodward, with an overall average of 0.61 . The lag times for the $5-60 \mathrm{~cm}$ correlations were generally longer than the $5-25 \mathrm{~cm}$ and they ranged from 2 to 26 days. The decreases in cross correlation strength with depth agree with the findings of Mahmood et al. (2012).

Similar results were attained for stations in Nebraska, as the maximum cross correlation for $10-25 \mathrm{~cm}$ ranged from 0.66 to 0.88 with an overall average of 0.79 . Lag times for the $10-25 \mathrm{~cm}$ cross correlations ranged from 0 to 5 days with an overall mean of 2 days. Maximum cross correlations for $10-50 \mathrm{~cm}$ ranged from 0.35 to 0.71 with an overall mean of 0.57 . Lag times for the $10-50 \mathrm{~cm}$ cross correlations ranged from 1 day to 26 days with an overall mean of 8 days. Finally, cross correlations between 10 and $100 \mathrm{~cm}$ ranged from 0.26 to 0.55 with an overall mean of 0.41 . Lag times for the $10-100 \mathrm{~cm}$ cross correlations ranged from 1 to 87 days with

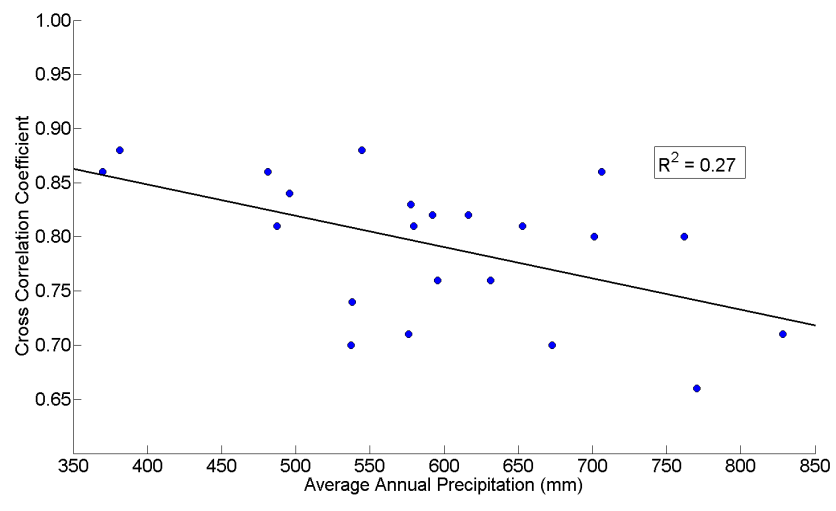

Fig. 7. Peak cross correlation $(r)$ between the 10 and $25 \mathrm{~cm}$ layers for all Nebraska sites versus the average annual precipitation. Each point represents one site.

an overall average of 33 days. Similar to the results from Oklahoma, cross correlations tend to decrease and lag times tend to increase as the depth increases.

We also calculated serial autocorrelation of daily nearsurface soil moisture data at each Oklahoma and $\mathrm{Ne}-$ braska station. The majority of autocorrelation functions (not shown) show strong autocorrelation of surface soil moisture at timescales of 1-5 days, but significantly decreased autocorrelation strength after 10 days. This suggests that the strong cross correlation between surface and root zone soil layers is partly due to the strong serial autocorrelation of surface soil moisture. However, beyond a week, autocorrelation quickly decreases and cross correlations are more strongly a function of the coupling between soil layers.

\subsection{Cross correlation strength-precipitation relationship}

To assess the influence of precipitation on the strength of soil layer coupling, we created scatter plots of the average annual precipitation, attained by the Parameter-elevation Regressions on Independent Slopes Model (PRISM) (http: //www.prism.oregonstate.edu/), with the peak cross correlation coefficient at each site. The relationship between precipitation and the strength of the cross correlations between the near-surface $(5$ or $10 \mathrm{~cm}$ ) and $25 \mathrm{~cm}$ soil moisture are shown in Figs. 6 and 7. In Oklahoma, there is a moderately strong positive relationship between the mean annual precipitation and $5-25 \mathrm{~cm}$ cross correlation coefficients $\left(R^{2}=0.33\right)$. This suggests that wetter locations (eastern Oklahoma) tend to have stronger coupling between soil moisture in the nearsurface and deeper in the soil. This is in agreement with previous research (Mahmood and Hubbard, 2007; Mahmood et al., 2012). However, Fig. 7 shows that the relationship between mean annual precipitation and $10-25 \mathrm{~cm}$ cross correlations in Nebraska are negative $\left(R^{2}=0.27\right)$. Mahmood et al. (2012) found that cross correlations between the 10 and $50 \mathrm{~cm}$ soil moisture in Nebraska were stronger in wetter 
locations. This is corroborated by our results in Oklahoma and contrasts with our results in Nebraska. The differences in the sign of the relationship between Nebraska and Oklahoma may be due to site-specific factors such as the near-surface depth of measurement $(5$ versus $10 \mathrm{~cm}$ ) or soil texture. However, we examined additional variables (soil texture, land cover, temperature) and were unable to determine why the relationship in Nebraska between cross correlation strength and mean annual precipitation is opposite of Oklahoma.

The cross correlation results suggest that associations between near-surface and root zone soil moisture are strong at the majority of observation sites in Oklahoma and Nebraska. Our results and those of previous studies (Houser et al., 1998; Calvet and Noilham, 2000; Walker et al., 2001; Mahmood et al., 2012) suggest that it is possible to use surface soil moisture estimates (either from satellites or in situ measurements) to make skillful predictions of root zone soil moisture. Therefore, in the next section we evaluate the accuracy of root zone soil moisture estimates that are based on near-surface soil moisture observations.

\subsection{Exponential filter}

Albergel et al. (2008) used a recursive exponential filter to predict root zone soil moisture from near-surface observations. The recursive formulation is used to predict the soil wetness index (SWI), a metric of soil moisture which standardizes volumetric soil water content by the minimum and maximum values attained over the entire period of record at each location. The recursive equation adopted from Albergel et al., (2008) for predicting soil moisture at time $t_{n}$, can be written as

$\mathrm{SWI}_{\mathrm{m} n}=\mathrm{SWI}_{\mathrm{m}(n-1)}+K_{n}\left(\mathrm{~ms}\left(t_{n}\right)-\mathrm{SWI}_{\mathrm{m}(n-1)}\right)$,

where $\mathrm{SWI}_{\mathrm{m}(n-1)}$ is the predicted root zone soil moisture estimate at $t_{n-1}, \operatorname{ms}\left(t_{n}\right)$ is the surface soil moisture estimate at $t_{n}$, and the gain $K$ at time $t_{n}$ is given by

$K_{n}=\frac{K_{n-1}}{K_{n-1}+e^{-\frac{t_{n}-t_{n-1}}{T}},}$

where $T$ represents the timescale of soil moisture variation, in day units. The filter is initialized with $\mathrm{SWI}_{\mathrm{m}(1)}=\mathrm{ms}\left(t_{1}\right)$ and $K_{1}=1$. Albergel et al. (2008) found that accuracy varied as a function of the $T$ value. They showed that each study site had an optimal $T$ value or $T_{\mathrm{opt}}$, which was characterized by the highest prediction accuracy as assessed by the Nash-Sutcliffe score. We applied the filter to soil moisture in Oklahoma and Nebraska and assessed the accuracy of the root zone soil moisture estimates using several metrics including mean absolute error (MAE), mean bias error (MBE), the Nash-Sutcliffe score (NS) and the coefficient of determination $\left(R^{2}\right)$. The $T$ parameter corresponding to the highest NS score was considered the $T_{\mathrm{opt}}$ for that station.

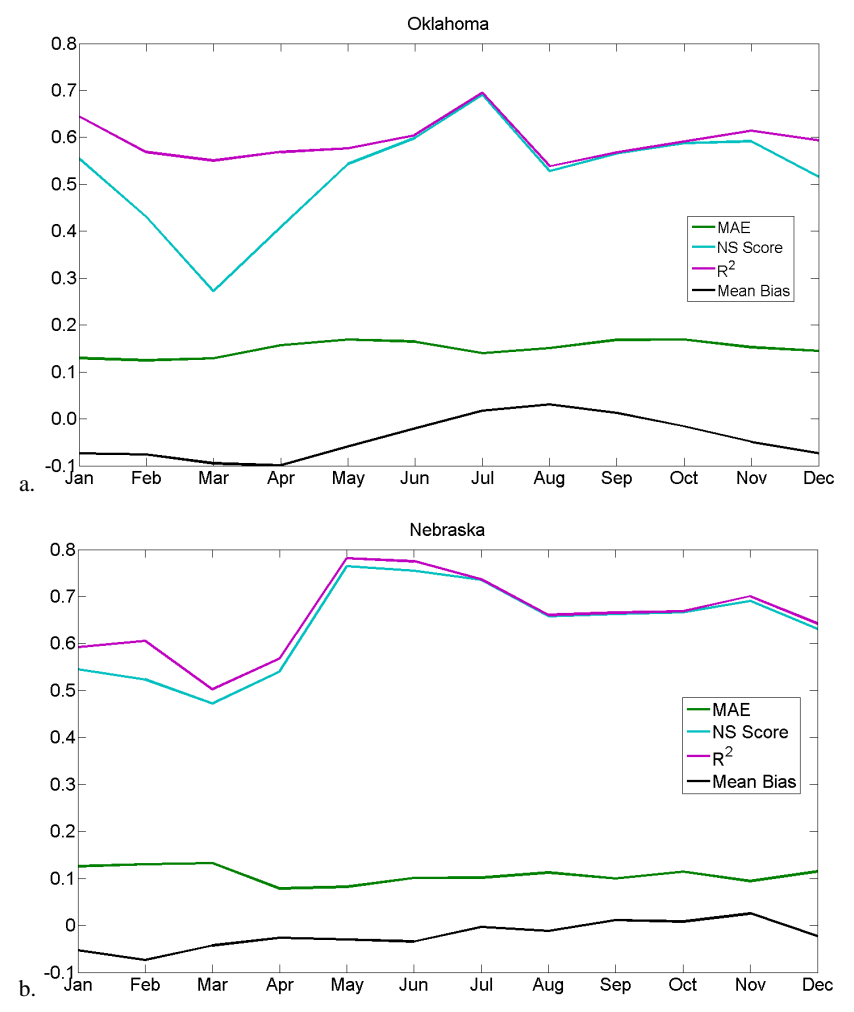

Fig. 8. Monthly average error metrics calculated from 5 to $25 \mathrm{~cm}$ soil moisture predictions. Results are averaged across all (a) Oklahoma and (b) Nebraska stations.

\subsubsection{Overall results}

Daily volumetric soil water content data are normalized (SWI) prior to the exponential filter. The SWI values are calculated using the maximum and minimum values from the entire daily volumetric water content time series (Oklahoma: 2000-2012, Nebraska: 2006-2010). Albergel et al. (2008) used $5 \mathrm{~cm}$ SWI to predict $30 \mathrm{~cm}$ SWI. Therefore, we applied this approach in Oklahoma by using daily $5 \mathrm{~cm}$ SWI to predict $25 \mathrm{~cm}$ SWI and in Nebraska we used $10 \mathrm{~cm}$ SWI to predict $25 \mathrm{~cm}$ SWI.

NS values between estimated $25 \mathrm{~cm}$ SWI and observed $25 \mathrm{~cm}$ SWI ranged from 0.07 to 0.84 with an overall average of $0.63 . R^{2}$ values ranged from 0.52 to 0.91 with an overall average of 0.73 . The optimum $T$ parameter, or $T_{\mathrm{opt}}$, is defined as the $T$ value at which the maximum observed-estimated root zone SWI NS score occurred for each station. $T_{\text {opt }}$ parameter values ranged from 2 to 22 days with an overall average of 8 days. Results were similar in Nebraska. NS values ranged from 0.08 to 0.83 with an overall average of 0.64 . $R^{2}$ values ranged from 0.51 to 0.84 with an overall average of 0.71. $T_{\mathrm{opt}}$ parameter values for sites in Nebraska ranged from 3 to 20 days with an overall average of 9 days.

Root zone SWI predictions were generally accurate and, based on NS scores, all were more accurate than simply using 
the mean root zone soil moisture as the prediction. Figure 8 shows plots of monthly average error metrics for (a) Oklahoma and (b) Nebraska. Root zone soil moisture estimates were generally higher than the soil moisture observations. Therefore, the mean bias (observed - predicted) is generally negative. For example, in Oklahoma (Fig. 8a) the mean bias is negative, except for a brief period between July and September. This period coincides with increased error, which is probably due to the relatively low soil moisture values in the root zone during the late summer period. Figure 8a also shows a marked drop in NS between February and April, with an NS $<0.3$ in March. Illston et al. (2004) observed four distinct seasonal soil moisture regimes in Oklahoma. The transition between the first regime and second regime (February-April) is characterized by the initiation of $5 \mathrm{~cm}$ soil moisture drying beginning in mid-March, while $25 \mathrm{~cm}$ soil moisture drying does not initiate until early-to-mid April. This could be one factor influencing the relatively low accuracy when predicting $25 \mathrm{~cm}$ soil moisture from $5 \mathrm{~cm}$ soil moisture during this period.

Figure $8 \mathrm{~b}$ shows monthly average error metrics from root zone soil moisture predictions in Nebraska. MAE and MBE are all relatively consistent across months; however, $R^{2}$ and NS values increase notably between April and May. Mahmood et al. (2012) found that this period in Nebraska was characterized by soil moisture recharge at all depths. Their results also showed that coupling between $10 \mathrm{~cm}$ soil moisture and deeper $(25,50,100 \mathrm{~cm})$ soil moisture was strongest under the wettest conditions. Predictions of root zone soil moisture from near-surface soil moisture should be most accurate during periods of soil moisture recharge.

\subsubsection{Optimum $T$ parameter}

We found the station-specific $T_{\text {opt }}$ parameter for each Oklahoma and Nebraska site, based on maximum NS value. Similar to the results from Albergel et al. (2008) we found that $T_{\text {opt }}$ varies considerably between stations. However, the monthly variability in NS shown in Fig. 9 suggests that $T_{\mathrm{opt}}$ could be a function of both space and time. Thus we quantified the influence of the overall soil moisture conditions on the variability of $T_{\text {opt }}$. To do this, we divided all of the near-surface SWI values from Oklahoma and Nebraska into 10 bins of equal range $(0.0-0.1,0.1-0.2$, etc.). Each nearsurface SWI observation was associated with a root zone soil moisture prediction and a corresponding NS value, measuring the accuracy of the prediction. We calculated the average NS value for each near-surface SWI bin. Figure 9 shows variability of the NS score and $T_{\text {opt }}$ parameter as a function of the near-surface SWI bin for sites in (a) Oklahoma and (b) Nebraska, respectively.

The highest NS scores at Oklahoma sites (Fig. 9a) are all attained at $T_{\text {opt }}$ between 3 and 10 days. When SWI is between 0.2 and 0.7 , NS scores stay positive with $T_{\text {opt }}$ values up to 40 days. However, when SWI is less than 0.2 or greater
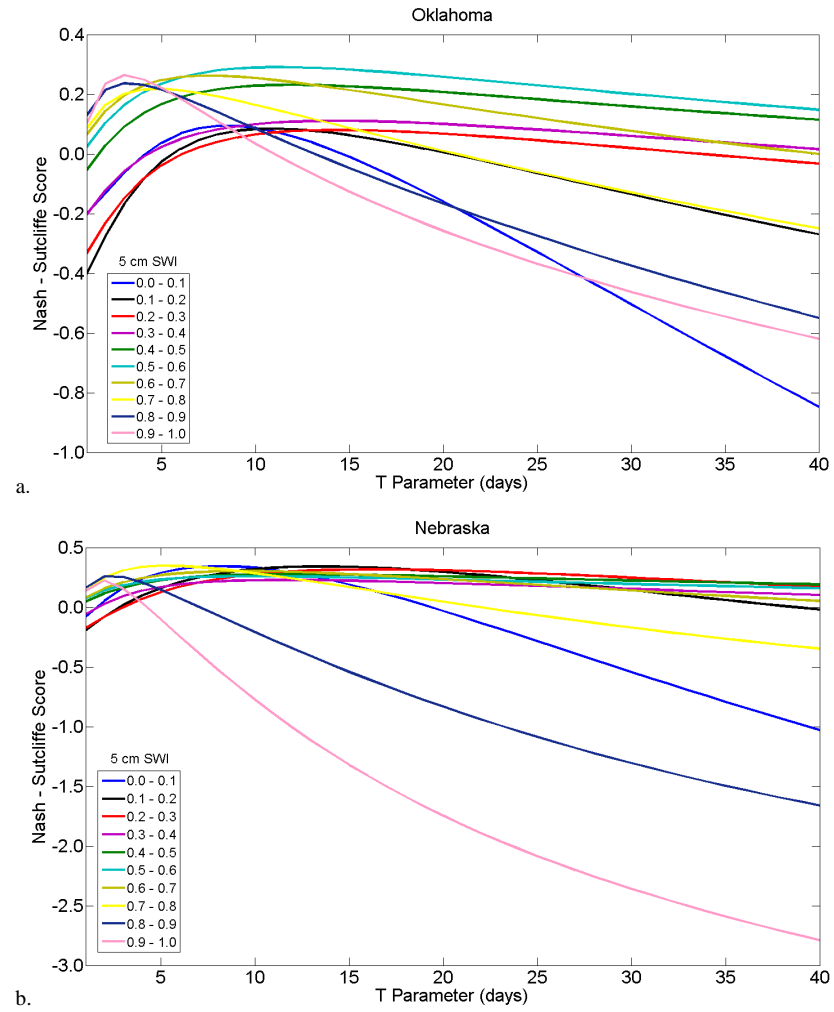

Fig. 9. Plots of the Nash-Sutcliffe score and the optimum $T$ parameter as a function of the SWI conditions in the near-surface soil layer. Results are based on all of the (a) Oklahoma and (b) Nebraska sites.

than 0.7 , NS scores quickly become negative when $T_{\text {opt }}$ is greater than 15-20 days. Like in Oklahoma sites, the highest NS at Nebraska sites occur at $T_{\text {opt }}$ between 2 and 7 days. Nebraska NS scores (Fig. 9b) also become negative when SWI is extremely dry $(<0.1)$ or wet $(>0.8)$ at $T_{\text {opt }}$ greater than 10 days. Therefore, the accuracy of the root zone soil moisture estimates are very sensitive to the $T_{\text {opt }}$ parameter when overlying near-surface soil moisture conditions are extremely dry or wet. Under more normal soil moisture conditions, the accuracy of the exponential filter method is nearly independent of the $T_{\text {opt }}$ parameter.

Albergel et al. (2008) found that although $T_{\mathrm{opt}}$ varied strongly between stations in their study, using the overall average $T_{\text {opt }}$ based on all stations did not result in a significant decrease in model accuracy. We evaluated this finding in our study region by initializing the exponential filter model using three different $T_{\text {opt }}$ parameters: (1) the overall average $T_{\text {opt }}$, which was 8 days for Oklahoma sites and 9 days for Nebraska sites, (2) site-specific $T_{\mathrm{opt}}$ parameters, and (3) $T_{\mathrm{opt}}$ based on the near-surface SWI, $\operatorname{ms}\left(t_{n}\right)$, conditions. Figure 10 shows box plots of the six error metrics calculated from the 3 different $T_{\text {opt }}$ parameters for (a) Oklahoma and (b) Nebraska sites, respectively. A paired Student's $t$ test was used to determine if the soil moisture estimates generated using these 

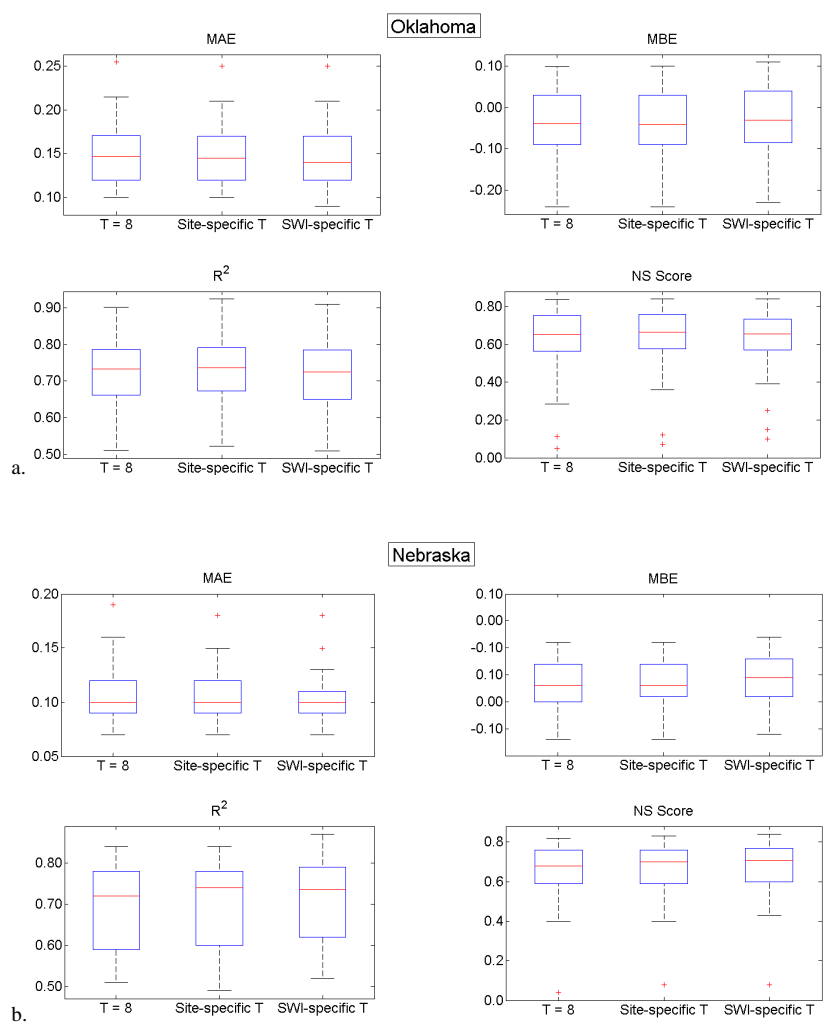

Fig. 10. Box plots of error metrics for the estimated root zone soil moisture averaged over all (a) Oklahoma and (b) Nebraska sites. Each box plot is generated from estimates made with one of three different optimum $\mathrm{T}$ parameters.

three different $T_{\text {opt }}$ parameters were statistically significant. Figure 10a shows that using an average $T_{\text {opt }}$ value when predicting root zone soil moisture values in Oklahoma does not result in significantly higher prediction error than using sitespecific or $\mathrm{ms}\left(t_{n}\right)$-specific $T_{\mathrm{opt}}$ parameters. Similar results are observed in Nebraska (Fig. 10b); the overall average $T_{\mathrm{opt}}$ parameter does not result in significantly higher error than the more dynamic $T_{\text {opt }}$ values.

We found that a network-average $T_{\mathrm{opt}}$ parameter can be used with the exponential filter to accurately predict root zone soil moisture using near-surface observations. Our results corroborate the findings of Albergel et al. (2008). We similarly assessed the variability of estimated soil moisture with a dynamic $T_{\text {opt }}$ parameter using $R^{2}$ instead of the NS score. The results were similar in that $T_{\text {opt }}$ parameter values of 8 and 9 days respectively resulted in the highest $R^{2}$ values. High levels of correspondence between assimilated root zone soil wetness and root zone observations are reported in several previous studies (Albergel et al., 2010; Barbu et al., 2011). Our results also show that the exponential filter method can accurately estimate root zone soil moisture in a different climatic regime (Great Plains) than the one in which it was developed and initially tested (Southern France).

\section{Estimating root zone soil moisture using SMOS}

Our results show that near-surface soil moisture is moderately to strongly coupled with soil moisture in the root zone (Sect. 3.2), and that near-surface SWI, based on observations, can be used to provide reasonably skillful predictions of root zone SWI (Sect. 3.3). Next we will evaluate the utility of the exponential decay filter for inferring root zone soil moisture from SMOS-derived surface soil moisture in Oklahoma and Nebraska. Once-daily SMOS surface retrievals between January and December 2011 were collected over 23 Oklahoma Mesonet sites and 22 Nebraska AWDN sites.

\subsection{Station-SMOS surface soil moisture comparison}

The correspondence between SMOS surface retrievals and near-surface in situ soil moisture observations provides the "baseline" error against which we will compare the accuracy of the SMOS estimates of root zone soil moisture. Data from each in situ station were compared directly to SMOS, and the coefficient of determination $\left(R^{2}\right)$ and NS score were used to assess the relationship strength between the two data sets. Because of the scale differences between stations and the satellite footprint, all error metrics are based on SWI instead of raw volumetric water content. This ensures both data sets have the same mean and range of values, thus making error assessment solely based on co-variability of the data sets. $R^{2}$ values in Oklahoma ranged from 0.32 to 0.71 with an overall mean of 0.56 . The relationship between observed and SMOS SWI was significant $(\alpha=0.05)$ at every Oklahoma station, indicating good correspondence between the two data sets. NS scores for the observed and SMOS SWI in Oklahoma ranged from 0.45 to 0.91 , with an overall mean of 0.71 . NS scores at all Oklahoma stations were positive, indicating good agreement between the two data sets.

The correspondence between near-surface SWI observations and SMOS SWI was similarly evaluated at stations in Nebraska. Nebraska $R^{2}$ values ranged from 0.00 to 0.33 , with an overall mean of 0.16 . NS scores over Nebraska were also significantly lower than those over Oklahoma. NS values in Nebraska ranged from -1.82 to 0.60 , with an overall mean of -0.48 . NS scores were positive at only 4 of the 22 stations in Nebraska. Clearly the relationship between observed SWI and SMOS SWI is stronger in Oklahoma than in Nebraska. Figure 11 shows scatter plots between observed SWI and SMOS SWI at (a) Oklahoma and (b) Nebraska stations. Although both plots show substantial scatter around the 1to-1 line, the data sets show better agreement in Oklahoma. There is evidence of a systematic bias in Nebraska. None of the days when the observed SWI in Nebraska was greater than 0.7 have a corresponding SMOS SWI greater than 0.7. The differences between Oklahoma and Nebraska suggest that the relationships between satellite soil moisture and in situ observations can vary significantly over space. 

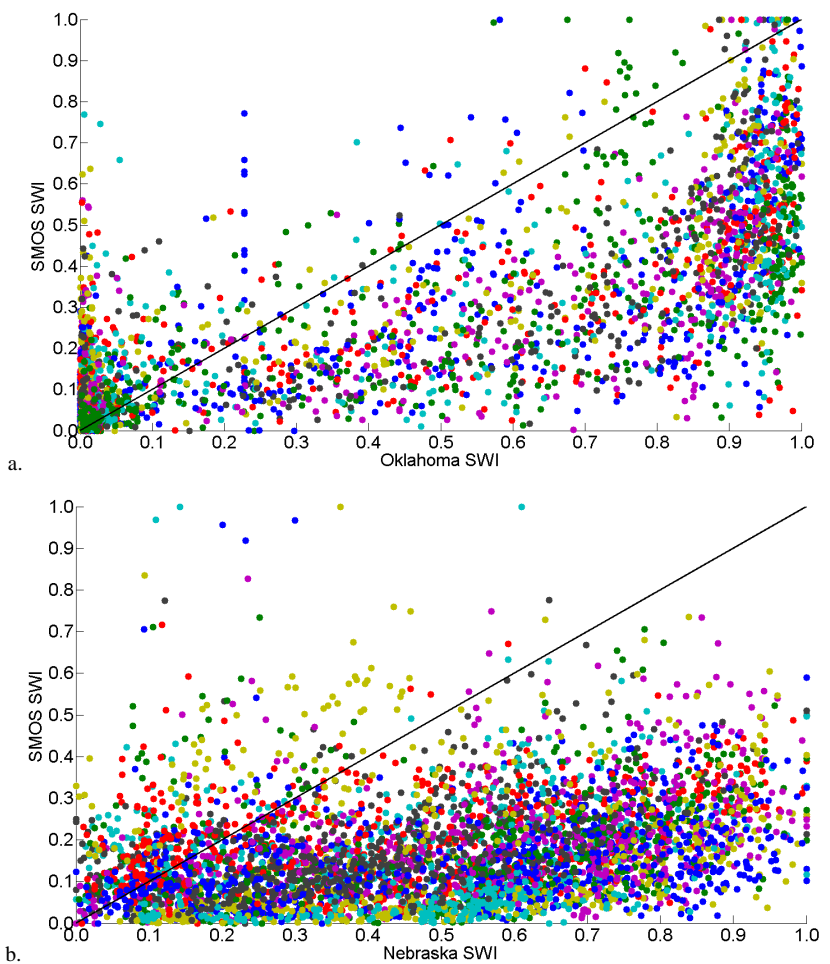

Fig. 11. Scatter plots of observed near-surface SWI and SMOS surface SWI for (a) Oklahoma and (b) Nebraska stations. Scatter points are color coded by individual stations.

\subsection{Station-SMOS root zone soil moisture comparison}

The exponential decay filter described in Sect. 3.3 is used to estimate root zone soil moisture from the SMOS surface estimates. Similar to results shown in Fig. 9, we varied the $T$ parameter from 1 to 25 days. Root zone SWI was estimated from SMOS surface data using each $T$ parameter. The performance of the filter under varying $T$ values was evaluated using the NS score, which was calculated based on comparing the root zone SWI estimated from SMOS with the in situ root zone SWI. Figure 12 shows how the accuracy of the estimated root zone SWI varies as a function of the $T$ parameter. Figure 12a shows results from Oklahoma, where accuracy peaks at $8-10$ days and begins to decline as $T$ approaches 25 days. Figure $12 \mathrm{~b}$ shows results from Nebraska, where accuracy consistently increases as the $T$ parameter increases to 25 days. For both cases, the accuracy of the method using the $T_{\mathrm{opt}}$ parameters derived from the in situ data sets (Oklahoma 8 days, Nebraska 9 days) is not substantially lower than the peak accuracy shown in Fig. 12. Therefore we used the original $T_{\text {opt }}$ parameter values to estimate root zone SWI using SMOS. Daily estimates of SMOS root zone SWI were compared to observed root zone SWI at stations in Oklahoma and Nebraska. Accuracy was measured using MAE, MBE, $R^{2}$ and NS score.
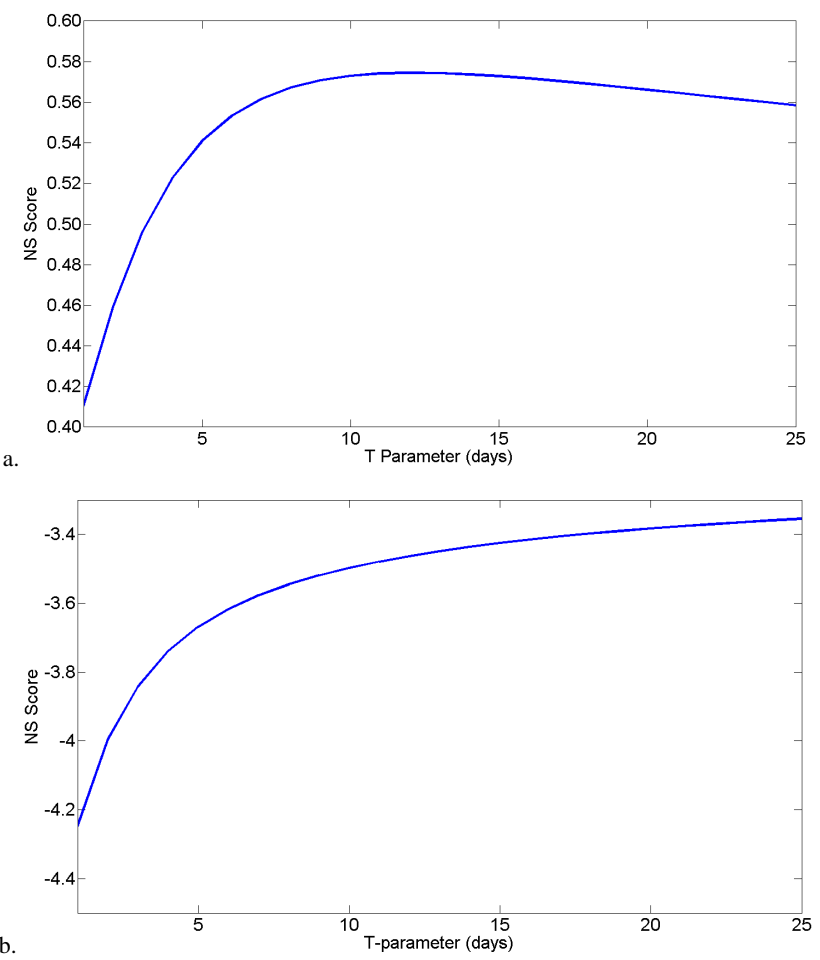

Fig. 12. Performance (NS score) of the exponential filter method when estimating root zone SWI from SMOS surface data as a function of T-parameter values. The top plot shows results for Oklahoma and the bottom shows results for Nebraska. NS scores are calculated between SMOS-estimated root zone soil moisture and in situ root zone soil moisture.

\subsubsection{SMOS results in Oklahoma}

SMOS root zone SWI estimates are compared to observed $25 \mathrm{~cm}$ SWI at all stations in Oklahoma. The relationship between SMOS surface retrievals and observed $5 \mathrm{~cm}$ soil moisture was used as the baseline by which to evaluate the SMOS root zone predictions. It can be used to determine how much of the error in the estimates of root zone SWI is due to the exponential filter method and how much is due to the uncertainties associated with the SMOS retrievals. Table 3 displays the overall mean, maximum and minimum values of MAE, MBE $R^{2}$, and NS score based on all of the stations in Oklahoma and Nebraska. All values in Table 3 are SWI (unitless). $R^{2}$ values ranged from 0.00 to 0.86 with an overall mean of 0.57 . In general the correspondence between the two data sets is weaker at the root zone than at the surface. However, $R^{2}$ values between root zone data are statistically significant at 20 of 22 Oklahoma stations. NS scores ranged from -0.14 to 0.92 , with an overall mean of 0.61 . NS scores at all but one Oklahoma stations are positive, indicating that there is good agreement between the observations and SMOS-based root zone SWI. 
Table 3. Statistics showing the correspondence of SMOS and station SWI data sets. Values under surface are calculated from station surfaceSMOS surface while values under root zone are calculated from station root zone - SMOS root zone. Table shows the mean, maximum and minimum over all sites. All values are SWI unitless.

\begin{tabular}{lcccccc}
\hline \multicolumn{3}{c}{ Oklahoma } & & & \multicolumn{3}{c}{ Nebraska } \\
\cline { 1 - 3 } \cline { 5 - 7 } \cline { 5 - 7 } MAE Mean & 0.27 & 0.33 & & MAE Mean & 0.34 & 0.26 \\
MAE Max & 0.43 & 0.50 & & MAE Max & 0.47 & 0.40 \\
MAE Min & 0.14 & 0.21 & & MAE Min & 0.12 & 0.15 \\
MBE Mean & 0.20 & 0.24 & & MBE Mean & 0.31 & 0.16 \\
MBE Max & 0.42 & 0.48 & & MBE Max & 0.46 & 0.36 \\
MBE Min & 0.04 & 0.02 & & MBE Min & 0.04 & -0.09 \\
$R^{2}$ Mean & 0.56 & 0.57 & & $R^{2}$ Mean & 0.16 & 0.24 \\
$R^{2}$ Max & 0.71 & 0.86 & & $R^{2}$ Max & 0.33 & 0.51 \\
$R^{2}$ Min & 0.32 & 0.00 & & $R^{2}$ Min & 0.00 & 0.00 \\
NS Mean & 0.71 & 0.61 & & NS Mean & -0.48 & 0.22 \\
NS Max & 0.91 & 0.92 & & NS Max & 0.60 & 0.54 \\
NS Min & 0.45 & -0.14 & & NS Min & -1.82 & -0.99 \\
\hline
\end{tabular}
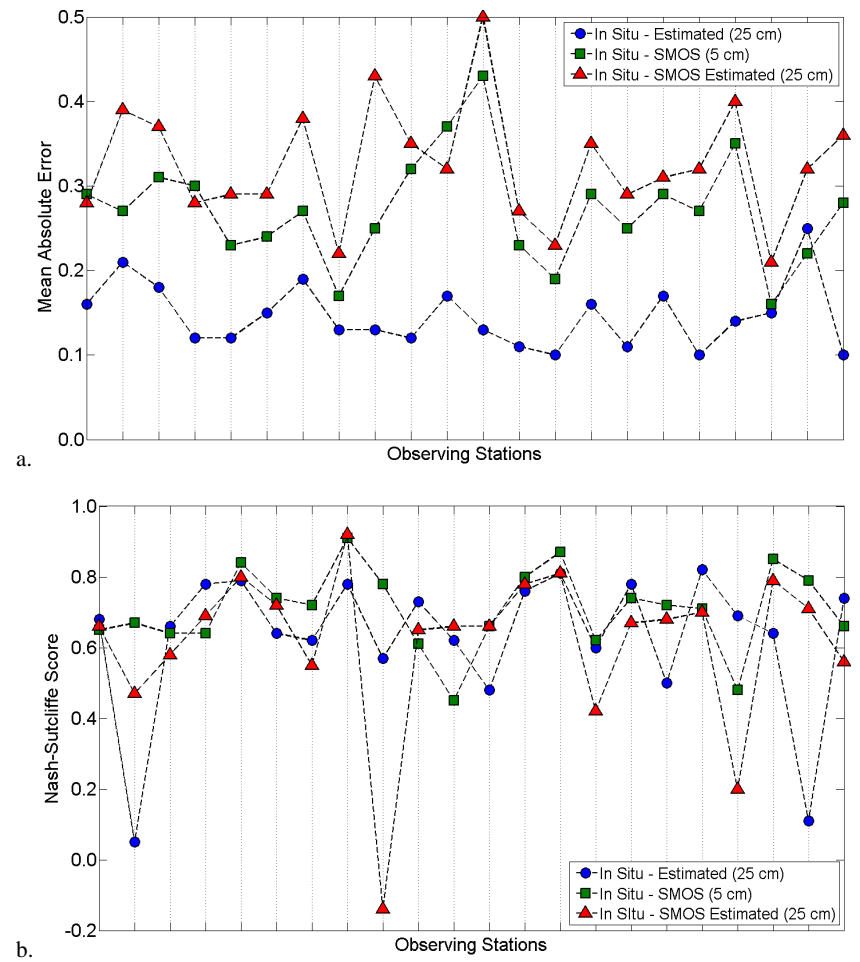

Fig. 13. The top plot shows MAE (SWI) at all Oklahoma stations. MAE is calculated between (blue circles) in situ surface observations and in situ root zone estimates, (green squares) in situ nearsurface observations and SMOS surface retrievals and (red triangles) in situ root zone observations and SMOS root zone estimates. The bottom plot shows NS scores at all Oklahoma stations for the same data set comparisons as in the top plot.
Partitioning error between the exponential filter and inherent SMOS-in situ differences gives a better description of where the largest discrepancies lie between observed and estimated data. Figure 13a shows MAE values at all Oklahoma observation stations. Error is reported between (blue circles) in situ root zone observations and root zone SWI estimated from in situ observations using the exponential filter, (green squares) in situ surface observations and SMOS surface retrievals, and (red triangles) in situ root zone observations and SWI estimated from SMOS using the exponential filter. At all but one Oklahoma station the MAE between SMOS surface retrievals and near-surface in situ observations was larger than the MAE between in situ root zone observations and root zone SWI estimated using the exponential filter. All but three stations had higher SMOS vs. observed root zone error than SMOS vs. observed surface error. On average, the SMOS-in situ surface comparison increased MAE by 0.13 (SWI) over Oklahoma in situ versus in situ root zone comparison. Also SMOS-in situ root zone comparison increased MAE by 0.05 (SWI) over SMOS-in situ surface comparison. This additional error represents roughly $20 \%$ of average SMOS-in situ surface comparison error, suggesting that the inherent differences between the SMOS and in situ products are larger than error created by the exponential filter method. Regardless, the MAE between SMOS and in situ data sets represent on average $46 \%$ of the observed mean SWI, and the exponential filter method increases the MAE to more than $50 \%$ of the observation mean.

Figure 13b shows a similar plot to $13 \mathrm{a}$, only it shows NS scores for the same three comparisons. On average, NS scores between SMOS and in situ surface SWI are 0.08 higher than NS scores between in situ root zone observations and in situ root zone estimates. In comparison, NS scores between SMOS root zone estimates and in situ root zone 

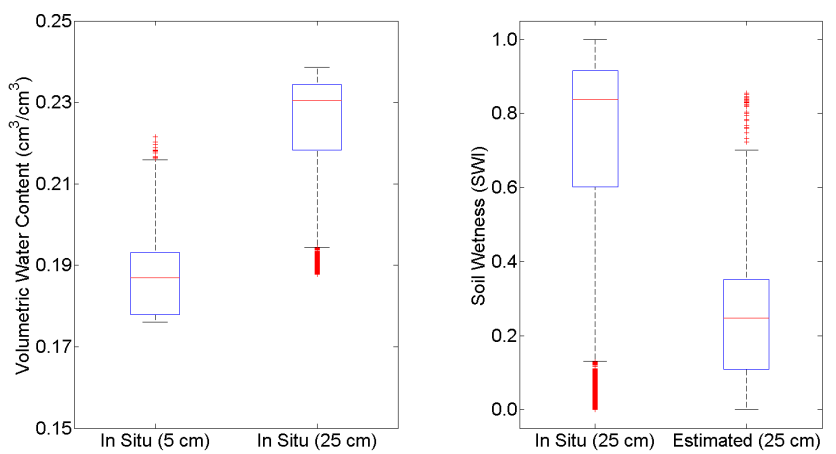

Fig. 14. Box plots of (left) volumetric water content at the 5 and $25 \mathrm{~cm}$ layers and (right) SWI from $25 \mathrm{~cm}$ in situ observations and $25 \mathrm{~cm}$ in situ estimates. The box plots show data from all Oklahoma stations.

observations decrease on average by 0.09 as compared with SMOS-in situ surface NS scores. In general, direct SMOSin situ comparisons lead to higher NS scores than comparing in situ observations to data sets estimated using the exponential filter. This suggests that in Oklahoma, although inherent SMOS-in situ differences are larger than error created by the exponential filter method, these differences do not result in lower NS scores.

Results presented in this section exclude those from the Apache, Oklahoma station. MAE calculated from the exponential filter method applied to in situ observations were exceptionally high, and NS scores were very low. Only when SMOS data were used did the MAE and NS scores resemble those from other Oklahoma stations. One issue with this station is the distribution of volumetric water content at the near-surface and root zone layers. Figure 14 shows box plots of (left) volumetric water content at the 5 and $25 \mathrm{~cm}$ layers, and (right) SWI calculated from $25 \mathrm{~cm}$ observations and estimated using the exponential filter method and $5 \mathrm{~cm}$ observations. Clearly the mean and distribution of volumetric water content between the two soil layers are significantly different, as the $5 \mathrm{~cm}$ observations and $25 \mathrm{~cm}$ SWI estimates have a right-skewed distribution and the $25 \mathrm{~cm}$ observations (volumetric water content and SWI) have a left-skewed distribution. The difference in distributions is mostly attributable to soil texture differences between the 5 and $25 \mathrm{~cm}$ sensor locations. Apache soils in the top $5 \mathrm{~cm}$ are approximately $77 \%$ sand content, corresponding to a saturated hydraulic conductivity of $213 \mathrm{~cm} \mathrm{day}^{-1}$ (Scott et al., 2013). The soil at $25 \mathrm{~cm}$ has a much lower sand content $(\sim 20 \%$ lower) and a higher clay content (10\% higher). Therefore, the saturated hydraulic conductivity is $73 \mathrm{~cm}^{-1 a y}{ }^{-1}$ at the $25 \mathrm{~cm}$ depth (Scott et al., 2013). Soil water moves through the nearsurface layer relatively quickly, resulting in the right-skewed volumetric water content distribution (Fig. 14). While soil water content at $25 \mathrm{~cm}$ tends to be much higher because of the reduced hydraulic conductivity. This suggests that the exponential filter method does not work well when soil textures
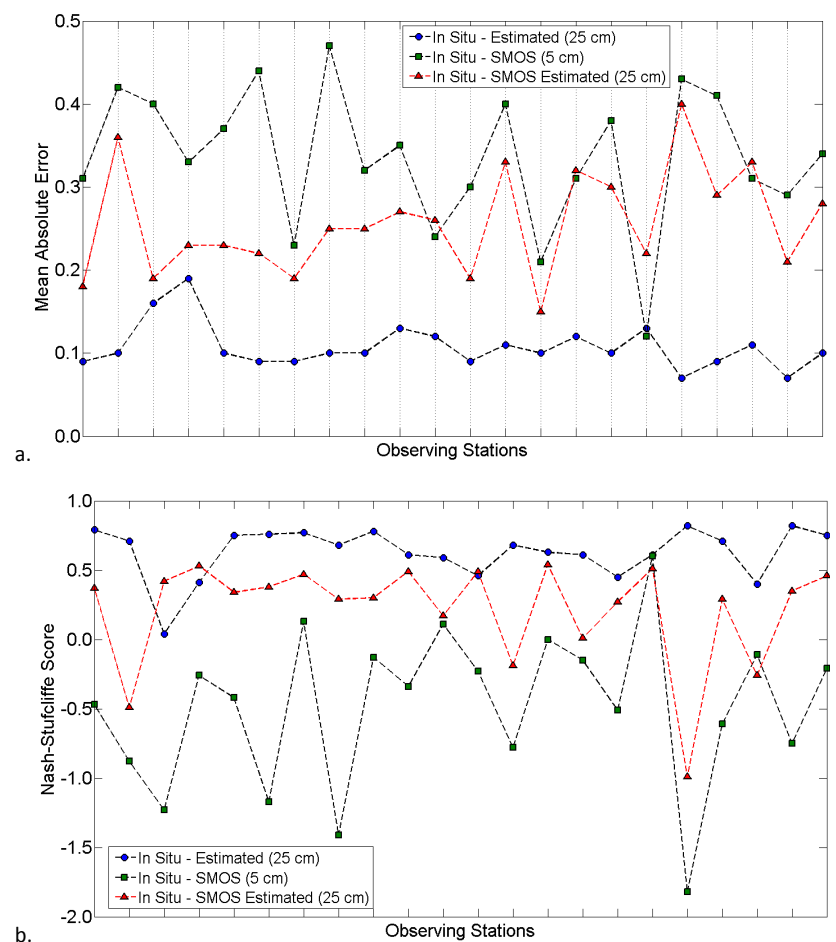

Fig. 15. The top plot shows MAE (SWI) at all Nebraska stations. MAE is calculated between (blue circles) in situ surface observations and in situ root zone estimates, (green squares) in situ nearsurface observations and SMOS surface retrievals and (red triangles) in situ root zone observations and SMOS root zone estimates. The bottom plot shows NS scores at all Nebraska stations for the same data set comparisons as in the top plot.

are not homogenous in the soil column, and SMOS-based estimates of root zone soil moisture must take into account how soil characteristics vary with depth to produce accurate results.

\subsubsection{SMOS results in Nebraska}

The analysis from Sect. 4.2.1 was also applied at 22 stations in Nebraska. $R^{2}$ values between SMOS root zone SWI estimates and Nebraska root zone SWI observations ranged from 0.00 to 0.51 , with an overall average of 0.24 . Nebraska root zone $R^{2}$ values are larger than the surface $R^{2}$ values at all but 3 stations. Overall, $R^{2}$ values between root zone data sets are statistically significant at 18 sites. NS scores ranged from -0.99 to 0.54 , with a mean of 0.22 . NS scores at 18 Nebraska stations are positive, indicating good agreement between the observed and SMOS root zone SWI. NS scores for the root zone are higher than at the surface at 20 of 22 stations in Nebraska.

Figure 15a shows MAE values from all Nebraska stations, similar to Fig. 14a for Oklahoma stations. Blue circles represent MAE between in situ root zone observations and estimates from the exponential filter, green squares represent 


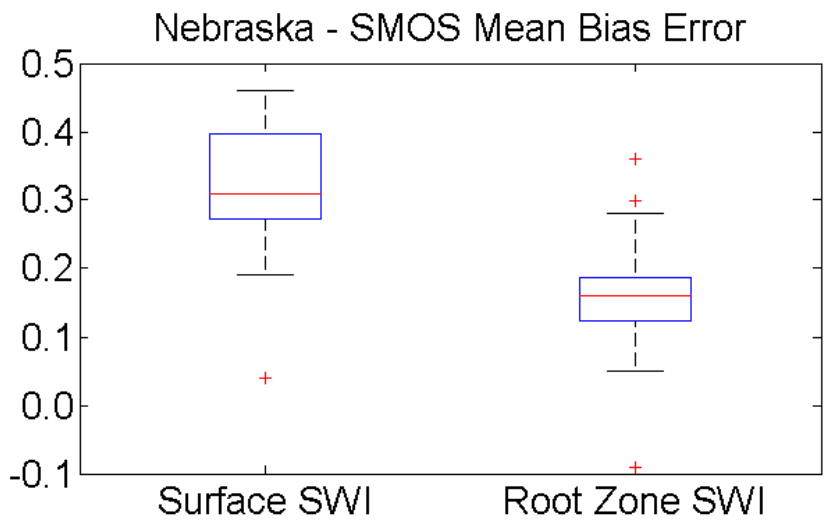

Fig. 16. Box plots show mean bias error calculated from (left) surface SWI data sets and (right) root zone SWI data sets. MBE is calculated between Nebraska stations and SMOS data.

MAE between in situ near-surface observations and SMOS surface retrievals and red triangles represent MAE between in situ root zone observations and SMOS root zone estimates. The differences (MAE) between SMOS and in situ observations at the surface are greater than the differences when comparing SMOS and in situ in the root zone. This agrees with our findings in Oklahoma; however, MAE at Nebraska stations is decreased between SMOS surface comparisons and root zone comparisons. This contrasts with the results from Oklahoma (Fig. 14a) and it is counterintuitive because the exponential filter method is expected to introduce additional error. Figure 16 shows the distribution of MBE between (left) surface comparison and (right) root zone comparison in Nebraska. All MBE values for the surface comparison are greater than zero, indicating that the observations are consistently wetter than SMOS. The MBE values in the root zone are much smaller. This indicates that the exponential filter method reduces the differences between the observed and SMOS-based SWI values in the root zone and thus greatly decreases the error (MAE and MBE) with respect to the surface SWI comparison.

Figure 15b shows NS scores from all Nebraska stations. The NS scores between SMOS and in situ surface observations are only positive at 3 out of 22 stations. It is somewhat surprising that NS scores between SMOS retrievals and nearsurface in situ observations are so low over Nebraska. One possible explanation is that Nebraska receives considerably more snow than Oklahoma between November and March. According to the National Weather Service's National Operational Hydrologic Remote Sensing Center (NOHRSC), most of Nebraska was snow covered until the end of March, 2011, and then again starting at the beginning of November. To test if snow cover influences the accuracy of SMOS retrievals, we examined the snow-free period (April-October). Figure 16 shows box plots of MAE between (left) SMOS surface retrievals and in situ near-surface observations and (right) SMOS root zone estimates and in situ root zone ob-
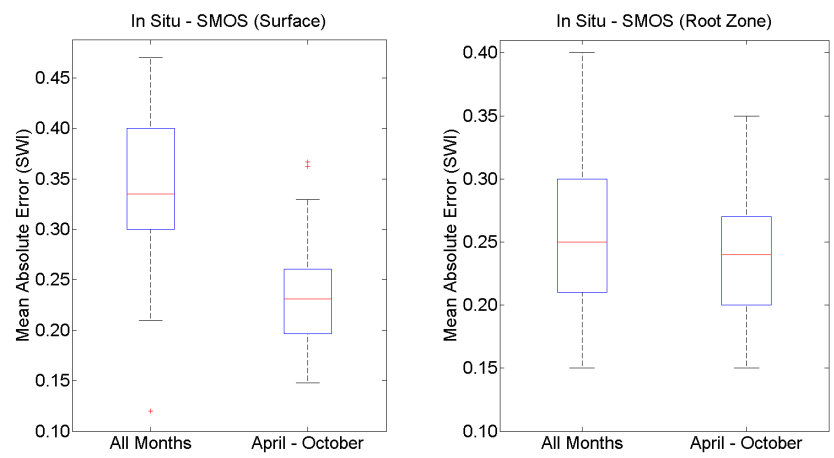

Fig. 17. Box plots show mean absolute error calculated from (left) surface SWI and (right) root zone SWI data sets. The left box plot in each panel shows MAE calculated over all months, while the right box plots in both panels show MAE calculated only during snowfree periods.

servations at all Nebraska stations. For both plots, the left box shows the MAE distribution over all months, JanuaryDecember, while the right box shows distributions between April and October. The mean surface MAE between January and December (0.33) is significantly higher than mean MAE between April and October (0.23). This suggests that SMOS soil moisture is more representative of observations during the growing season, particularly when there is no snow cover. However, the significant improvement in surface soil moisture accuracy does not translate to the root zone (Fig. 16), as there is no significant difference between SMOS root zone estimates and in situ root zone observations regardless of snow cover. Figure 17 compares the MAE values between in situ and SMOS at (left) the surface and (right) in the root zone for the snow-free period versus the entire year. MAE for the SMOS surface retrievals and in situ near-surface observations are significantly lower between April and October than January-December, however there is not a significant MAE difference in the root zone.

After accounting for the influence of snow cover, the results over Nebraska are similar to those over Oklahoma. In general the MAE of root zone estimates from the exponential filter represent $10-20 \%$ of the overall in situ SWI mean. In comparison, differences between SMOS surface retrievals and near-surface in situ observations represented $20-40 \%$ of the overall in situ SWI mean. Despite the large MAE, NS scores at the majority of Nebraska stations are positive after accounting for snow cover.

Overall, the results from Oklahoma and Nebraska suggest that (1) the exponential filter can be a reasonably skillful method for estimating root zone soil moisture (mean error is $\sim 10 \%$ ) and (2) SMOS surface retrievals do not correspond well with in situ observations, but specifically for Nebraska, compatibility increases when only comparing SMOS over a land cover without snow. Our findings are generally in agreement with previous studies. Wagner et al. (1999) evaluated 
root zone soil moisture estimates from ERS scatterometer data using multiple stations in Ukraine. The strength of correspondence between the satellite estimates and stationbased observations was similar to our results. Ceballos et al. (2005) also found strong correlation $\left(R^{2}=0.75\right)$ between root zone soil wetness derived from ERS scatterometer surface retrievals and in situ observations over the semi-arid Duero Basin in Spain. Brocca et al. (2013) found strong correspondence between ASCAT-derived SWI and in situ soil moisture observations in northern Italy, with $R^{2}$ values exceeding 0.75 .

\section{Summary and conclusions}

Satellite soil moisture retrievals are valuable because they provide better spatial coverage than in situ soil moisture observations. SMOS measures soil water content in the top few centimeters and thus cannot directly determine root zone soil moisture conditions. Therefore, it is important to evaluate the degree of association between near-surface and root zone soil moisture when attempting to estimate root zone moisture using satellite retrievals. This study quantified the coupling strength between surface and root zone soil moisture. It also evaluated whether the exponential filter can be used to predict root zone soil moisture. Finally, the accuracy of SMOSbased estimates of root zone soil moisture derived using the exponential filter were evaluated using in situ observations.

Cross correlation analysis was used to examine the relationship strength between near-surface and root zone soil moisture at 33 sites in Oklahoma and 22 sites in Nebraska. The results revealed generally strong relationships between soil moisture in the near-surface and root zone. However, the lag time at which the two layers correlated most strongly varied depending on climatic conditions. After the strong association between near-surface and root zone soil moisture was established, an exponential filter method from Albergel et al. (2008) was used to estimate root zone soil moisture based on near-surface observations. This method was shown to have skill. However, accuracy diminished during times of transition between soil moisture recharge (wet) and utilization (dry) phases. The primary coefficient of the exponential filter $\left(T_{\mathrm{opt}}\right)$ was sensitive to soil wetness and varied considerably based on the climatic regime. The exponential filter method also did not perform well when soil characteristics varied considerably with depth.

The exponential filter method was used to estimate root zone soil moisture based on SMOS surface retrievals. The root zone estimates were compared to $25 \mathrm{~cm}$ soil moisture observations. SMOS root zone soil wetness and in situ root zone observations in Oklahoma and Nebraska show good correspondence, with $R^{2}$ exceeding 0.90 at several sites. Specifically root zone soil moisture estimated using the exponential filter did not correlate well with root zone observations when the distributions of in situ volumetric water content at the near-surface and root zone are different; as in Apache, Oklahoma. SMOS correspondence with in situ observations varied, but in general resulted in positive NS scores. SMOS corresponded most strongly with in situ observations when the land surface was free of snow cover.

The main conclusions of this study are (1) soil moisture in near-surface and root zone layers in Oklahoma and Nebraska are strongly coupled, (2) the exponential filter method can provide accurate estimates of root zone soil moisture as long as soil characteristics are relatively homogeneous throughout the soil column and (3) SMOS surface soil moisture retrievals can be used with the exponential filter method to estimate root zone soil moisture over Oklahoma and Nebraska with reasonable skill, except when there is snow cover.

Acknowledgements. This research was funded by the National Science Foundation (award AGS-1056796). We would also like to acknowledge data provided by the Oklahoma Mesonet and Automated Weather Data Network for in situ soil moisture.

Edited by: N. Verhoest

\section{References}

Albergel, C., Rüdiger, C., Pellarin, T., Calvet, J.-C., Fritz, N., Froissard, F., Suquia, D., Petitpa, A., Piguet, B., and Martin, E.: From near-surface to root-zone soil moisture using an exponential filter: an assessment of the method based on in-situ observations and model simulations, Hydrol. Earth Syst. Sci., 12, 1323-1337, doi:10.5194/hess-12-1323-2008, 2008.

Albergel, C., Rüdiger, C., Carrer, D., Calvet, J.-C., Fritz, N., Naeimi, V., Bartalis, Z., and Hasenauer, S.: An evaluation of ASCAT surface soil moisture products with in-situ observations in Southwestern France, Hydrol. Earth Syst. Sci., 13, 115-124, doi:10.5194/hess-13-115-2009, 2009.

Albergel, C., Calvet, J.-C., Mahfouf, J.-F., Rüdiger, C., Barbu, A. L., Lafont, S., Roujean, J.-L., Walker, J. P., Crapeau, M., and Wigneron, J.-P.: Monitoring of water and carbon fluxes using a land data assimilation system: a case study for southwestern France, Hydrol. Earth Syst. Sci., 14, 1109-1124, doi:10.5194/hess-14-1109-2010, 2010.

Al Bitar, A., Leroux, D., Kerr, Y. H., Merlin, O., Richaume, P., Sahoo, A., and Wood, E. F.: Evaluation of SMOS soil moisture products over continental US using the SCAN/SNOTEL network. Geoscience and Remote Sensing, IEEE Trans., 50, 15721586, 2012.

Alfieri, L., Claps, P., D’Odorico, P., Laio, F., and Over, T. M.: An analysis of the soil moisture feedback on convective and stratiform precipitation, J. Hydrometeorol., 9, 280-291, 2008.

Barbu, A. L., Calvet, J.-C., Mahfouf, J.-F., Albergel, C., and Lafont, S.: Assimilation of Soil Wetness Index and Leaf Area Index into the ISBA-A-gs land surface model: grassland case study, Biogeosciences, 8, 1971-1986, doi:10.5194/bg-8-1971-2011, 2011.

Basara, J. B. and Crawford, K. C.: Linear relationships between root-zone soil moisture and atmospheric processes in the planetary boundary layer, J. Geophys. Res., 107, 4274, doi:10.1029/2001JD000633, 2002. 
Brocca, L., Melone, F., Moramarco, T., Wagner, W., Naeimi, V., Bartalis, Z., and Hasenauer, S.: Improving runoff prediction through the assimilation of the ASCAT soil moisture product, Hydrol. Earth Syst. Sci., 14, 1881-1893, doi:10.5194/hess-141881-2010, 2010.

Brocca, L., Hasenauer, S., Lacava, T., Melone, F., Moramarco, T., Wagner, W., Dorigo, W., Matgen, P., Martínez-Fernándz, J., Llorens, P., Latron, J., Martin, C., and Bittelli, M.: Soil moisture estimation through ASCAT and AMSR-E sensors: An intercomparison and validation study across Europe, Remote Sens. Environ., 115, 3390-3408, 2011.

Brocca, L., Tarpanelli, A., Moramarco, T., Melone, F., Ratto, S. M., Cauduro, M., Ferraris, S., Berni, N., Ponziani, F., Wagner, W., and Melzer, T.: Soil moisture estimation in alpine catchments through modeling and satellite observations, Vadose Zone Hydrol., 12, 1-10, 2013.

Calvet, J. and Noilham, J.: From near-surface to root-zone soil moisture using year-round data. J. Hydrometeo. 1, 393-411, 2000.

Ceballos, A., Scipal, K., Wagner, W., and Martínez-Fernández, J.: Validation of ERS scatterometer-derived soil moisture data in the central part of the Duero Basin, Spain, Hydrol. Process., 19, 1549-1566, 2005.

Collow, T. W., Robock, A., Basara, J. B., and Illston, B. G.: Evaluation of SMOS retrievals of soil moisture over the central United States with currently available in situ observations, J. Geophys. Res., 117, D09113, doi:10.1029/2011JD017095, 2012.

Cosh, M. H., Ochsner, T., Basara, J., and Jackson, T. J.: The SMAP in situ soil moisture sensor testbed: Comparing in situ sensors for satellite validation, in: Geoscience and Remote Sensing Symposium (IGARSS), 2010 IEEE International, 2010.

Crow, W. T. and Wood, E. F.: The assimilation of remotely sensed soil brightness temperature imagery into a land surface model using ensemble Kalman filtering: A case study based on ESTAR measurements during SGP97, Adv. Water Resour., 26, 137-149, 2003.

Draper, C., Mahfouf, J., and Walker, J.: An EKF assimilation of AMSR-E soil moisture into the ISBA land surface scheme, J. Geophys. Res.-Atmos., 114, 1984-2012, 2009.

Entekhabi, D., Nioku, E. G., O’Neill, P. E., Kellogg, K. H., Crow, W. T., Edelstein, W. N., Entin, J. K., Goodman, S. D., Jackson, T. J., Johnson, J., Kimball, J., Piepmeier, J. R., Koster, R. D., Martin, N., McDonald, K. C., Moghaddam, M., Moran, S., Reichle, R., Shi, J.-C., Spencer, M. W., Thurman, S. W., Leung, T., and Van Zyl, J.: The Soil Moisture Active Passive (SMAP) Mission, Proc. IEEE., 98, 704-716, 2010.

Frye, J. D. and Mote, T. L.: Convection initiation along soil moisture boundaries in the southern Great Plains, Mon. Weather Rev., 138, 1140-1151, 2010.

Georgakakos, K. P. and Bae, D.: Climatic variability of soil water in the American Midwest: Part 2. Spatio-temporal analysis, J. Hydrol., 162, 379-390, 1994.

Hain, C. R., Crow, W. T., Anderson, M. C., and Mecikalski, J. R.: An ensemble Kalman filter dual assimilation of thermal infrared and microwave satellite observations of soil moisture into the Noah land surface model, Water Resour. Res., 48, W11517, doi:10.1029/2011WR011268, 2012.
Houser, P. R., Shuttleworth, W. J., Famiglietti, J. S., Gupta, H. V., Syed, K. H., and Goodrich, D. C.: Integration of soil moisture remote sensing and hydrologic modeling using data assimilation, Water Resour. Res. 34, 3405-3420, 1998.

Hsu, K., Li, J., and Sorooshian, S.: To improve model soil moisture estimation in arid/semi-arid region using in situ and remote sensing information, Paddy Water Environ., 10, 165-173, 2012.

Illston, B. G., Basara, J. B., and Crawford, K. C.: Seasonal to interannual variations of soil moisture measured in Oklahoma, Int. J. Climatol., 24, 1883-1896, 2004.

Illston, B. G., Basara, J. B., Fiebrich, C. A., Crawford, K. C., Hunt, E., Fisher, D. K., Elliott, R., and Humes, K.: Mesoscale monitoring of soil moisture across a statewide network, J. Atmos. Ocean. Technol., 25, 167-182, 2008.

Jackson, T. J., Bindlish, R., Cosh, M. H., Zhao, T., Starks, P. J., Bosch, D. D., Seyfried, M., Moran, M. S., Goodrich, D. C., and Kerr, Y. H.: Validation of Soil Moisture and Ocean Salinity (SMOS) soil moisture over watershed networks in the US. Geoscience and Remote Sensing, IEEE Trans., 50, 1530-1543, 2012.

Kerr, Y. H., Waldteufel, P., Wigneron, J.-P., Delwart, S., Cabot, F., Boutin, J., Escorihuela, M.-J., Font, J., Reul, N., Gruhier, C., Juglea, S. E., Drinkwater, M. R., Hahne, A., Martin-Neira, M., and Mecklenburg, S.: The SMOS mission: New tool for monitoring key elements of the global water cycle, IEEE Trans., 98, 666687, 2010.

Kerr, Y. H., Waldteufel, P., Richaume, P., Wigneron, J.-P., Ferrazzoli, P., Mahmoodi, A., Al Bitar, A., Cabot, F., Gruhier, C., Juglea, S. E., Leroux, D., Mialon, A., and Delwart, S.: The SMOS soil moisture retrieval algorithm, Geosci. Remote Sens., 50, 1384-1403, 2012.

Koster, R. D., Dirmeyer, P. A., Guo, Z., Bonan, G., Chan, E., Cox, P., Gordon, C., Kanae, S., Kowalczyk, E., and Lawrence, D.: Regions of strong coupling between soil moisture and precipitation, Science, 305, 1138-1140, 2004.

Legates, D. R., Mahmood, R., Levia, D. F., DeLiberty, T. L., Quiring, S. M., Houser, C., and Nelson, F. E.: Soil moisture: A central and unifying theme in physical geography, Prog. Phys. Geogr., 35, 65-86, 2011.

Li, B., Rodell, M., Zaitchik, B. F., Reichle, R. H., Koster, R. D., and van Dam, T. M.: Assimilation of GRACE terrestrial water storage into a land surface model: evaluation and potential value for drought monitoring in western and central Europe, J. Hydrol., 446-447, 103-115, 2012.

Mahmood, R. and Hubbard, K. G.: An analysis of simulated longterm soil moisture data for three land uses under contrasting hydroclimatic conditions in the Northern Great Plains, J. Hydrometeorol., 5, 160-179, 2004.

Mahmood, R. and Hubbard, K. G.: Relationship between soil moisture of near surface and multiple depths of the root zone under heterogeneous land uses and varying hydroclimatic conditions, Hydrol. Process., 21, 3449-3462, 2007.

Mahmood, R., Littell, A., Hubbard, K. G., and You, J.: Observed data-based assessment of relationships among soil moisture at various depths, precipitation, and temperature, Appl. Geogr., 34, 255-264, 2012.

McPherson, R. A.: A review of vegetation-atmosphere interactions and their influences on mesoscale phenomena, Prog. Phys. Geogr., 31, 262-285, 2007. 
Meng, L. and Quiring, S. M.: Observational relationship of sea surface temperatures and precedent soil moisture with summer precipitation in the US Great Plains, Int. J. Climatol., 30, 884-893, 2010.

Pal, J. S. and Eltahir, E. A. B.: Pathways relating soil moisture conditions to future summer rainfall within a model of the landatmosphere system, 2001.

Prigent, C., Aires, F., Rossow, W. B., and Robock, A.: Sensitivity of satellite microwave and infrared observations to soil moisture at a global scale: Relationship of satellite observations to in situ soil moisture measurements, J. Geophys. Res.-Atmos., 110, 19842012, 2005.

Reichle, R. H. and Koster, R. D.: Global assimilation of satellite surface soil moisture retrievals into the NASA Catchment land surface model, Geophys. Res. Lett., 32, L02404, doi:10.1029/2004GL021700, 2005.

Sabater, J. M., Jarlan, L., Calvet, J., Bouyssel, F., and De Rosnay, P.: From near-surface to root-zone soil moisture using different assimilation techniques, J. Hydrometeorol., 8, 194-206, 2007.

Taylor, C. M., Parker, D. J., and Harris, P. P.: An observational case study of mesoscale atmospheric circulations induced by soil moisture, Geophys. Res. Lett., 34, L15801, doi:10.1029/2007GL030572, 2007.
Taylor, C. M., de Jeu, R. A., Guichard, F., Harris, P. P., and Dorigo, W. A.: Afternoon rain more likely over drier soils, Nature, 489, 423-426, 2012.

Wagner, W., Lemoine, G., and Rott, H.: A method for estimating soil moisture from ERS scatterometer and soil data, Remote Sens. Environ., 70, 191-207, 1999.

Walker, J. P., Willgoose, G. R., and Kalma, J. D.: One-dimensional soil moisture profile retrieval by assimilation of near-surface measurements: A simplified soil moisture model and field application, J. Hydrometerol., 2, 356-373, 2001.

Wu, W. and Dickinson, R. E.: Time Scales of Layered Soil Moisture Memory in the Context ofLand-Atmosphere Interaction, J. Climate, 17, 2752-2764, 2004.

Wu, W., Geller, M. A., and Dickinson, R. E.: The response of soil moisture to long-term variability of precipitation, J. Hydrometeorol., 3, 604-613, 2002.

You, J., Hubbard, K. G., Mahmood, R., Sridhar, V., and Todey, D.: Quality Control of Soil Water Data in Applied Climate Information System - Case Study in Nebraska, J. Hydrol. Eng., 15, 200-209, 2010. 